\title{
On the Variability of Charleston South Carolina Winds, Atmospheric Temperatures, Water Levels, Waves and Precipitation
}

\author{
L. J. Pietrafesa',2, P. T. Gayes¹, S. Bao', T. Yan³, D. A. Dickey², D. D. Carpenter ${ }^{1}$, T. G. Carver1 \\ ${ }^{1}$ Coastal Carolina University, Conway, South Carolina, USA \\ ${ }^{2}$ North Carolina State University, Raleigh, North Carolina, USA \\ ${ }^{3}$ Shaw University, Raleigh, North Carolina, USA \\ Email: ljpietra@ncsu.edu,sbao@coastal.edu,ptgayes@coastal.edu, tyan@shaw.edu,dickey@stat.ncsu.edu, \\ ddcarpenter@coastal.edu
}

How to cite this paper: Pietrafesa, L.J., Gayes, P.T., Bao, S., Yan, T., Dickey, D.A., Carpenter, D.D. and Carver, T.G. (2021) On the Variability of Charleston South Carolina Winds, Atmospheric Temperatures, Water Levels, Waves and Precipitation. International Journal of Geosciences, 12, 499-516. https://doi.org/10.4236/ijg.2021.125027

Received: April 16, 2021

Accepted: May 25, 2021

Published: May 28, 2021

Copyright $\odot 2021$ by author(s) and Scientific Research Publishing Inc. This work is licensed under the Creative Commons Attribution International License (CC BY 4.0).

http://creativecommons.org/licenses/by/4.0/ cc) (i) Open Access

\begin{abstract}
Atmospheric winds, air temperatures, water levels, precipitation and oceanic waves in the Charleston South Carolina (SC) coastal zone are evaluated for their intrinsic, internal variability over temporal scales ranging from hours to multi-decades. The purpose of this study was to bring together a plethora of atmospheric and coastal ocean state variable data in a specific locale, to assess temporal variabilities and possible relationships between variables. The questions addressed relate to the concepts of weather and climate. Data comprise the basis of this study. The overall distributions of atmospheric and coastal oceanic state variable variability, including wind speed, direction and kinematic distributions and state variable amplitudes over a variety of time scales are assessed. Annual variability is shown to be highly variable from year to year, making arithmetic means mathematically tractable but physically meaningless. Employing empirical and statistical methodologies, data analyses indicate the same number of intrinsic, internal modes of temporal variability in atmospheric temperatures, coastal wind and coastal water level time series, ranging from hours to days to weeks to seasons, sub-seasons, annual, multi-year, decades, and centennial time scales. This finding demonstrates that the atmosphere and coastal ocean in a southeastern U.S. coastal city are characterized by a set of similar frequency and amplitude modulated phenomena. Kinematic hodograph descriptors of atmospheric winds reveal coherent rotating and rectilinear particle motions. A mathematical statistics-based wind to wave-to-wave algorithm is developed and applied to offshore marine buoy data to create an hour-by-hour forecast capability from 1 to 24 hours; with confidence levels put forward. This affects a different approach to the conventional deterministic model forecasting of waves.
\end{abstract}




\section{Keywords}

Charleston Atmospheric Temperature, Winds, Water Level, Precipitation, Oceanic Waves, Temporal Scales of Variability, Kinematics of the Winds, Winds Predict Waves

\section{Introduction}

The atmospheric weather to sub-seasonal variability in southern climates is very difficult to predict, as southern U.S. states are in highly convective environments most of the year. Interactive couplings of land, ocean and atmospheric boundary layers complicate coastal zone weather forecasting, particularly of winds and precipitation. This is also true of oceanic coastal water levels and wave fields in southern environs [1]. The conventional perspective is that the system is highly chaotic and unpredictable. Extending weather forecasts to seasonal to sub-seasonal forecasts are also seemingly problematic. In this study, we investigate state variable atmospheric and oceanic time series of air temperature, winds and water level data at a specific locale, Charleston South Carolina, to evaluate coherent structures or the lack thereof in the relative atmospheric temperatures and coastal sea level fields. Empirical [2] [3] [4] and statistical [5] [6] methodologies are employed on the data sets, which contain highly nonlinear and non-stationary data. This is a data-based study to reveal what weather-to-climate phenomena are present at a locale in the southeastern USA.

\section{Materials}

Data employed in this study are from the National Oceanic and Atmospheric Administration (NOAA) National Centers for Environmental Information (NCEI) archives (https://www.ncei.noaa.gov/).

\section{Methods}

In this study, empirical methods are employed to deal with non-stationary and nonlinear data time series [2] [3] [4]. Kinematical, hodograph descriptors methodologies employed are described in [7] [8]. Statistical methodologies are presented in [6]. Inertial oscillation discussions in the ocean derive from the study reported on in [9]. All of these mathematical methodologies are data based and none required deterministic numerical modeling.

\section{Results}

Figure 1 presents the Charleston Air Temperature time series and Ensemble Empirical Mode Decomposition-Intrinsic Mode Functions (EEMD-IMFs) as developed in [2] [3] [4]. The panel is the hourly time series ranging from 0 to $40^{\circ} \mathrm{C}$. For our purposes, we used only a portion of the total 1895-2019, 125-year time series, pulling out the 77-year hourly time series, extending from 1943-2019. 


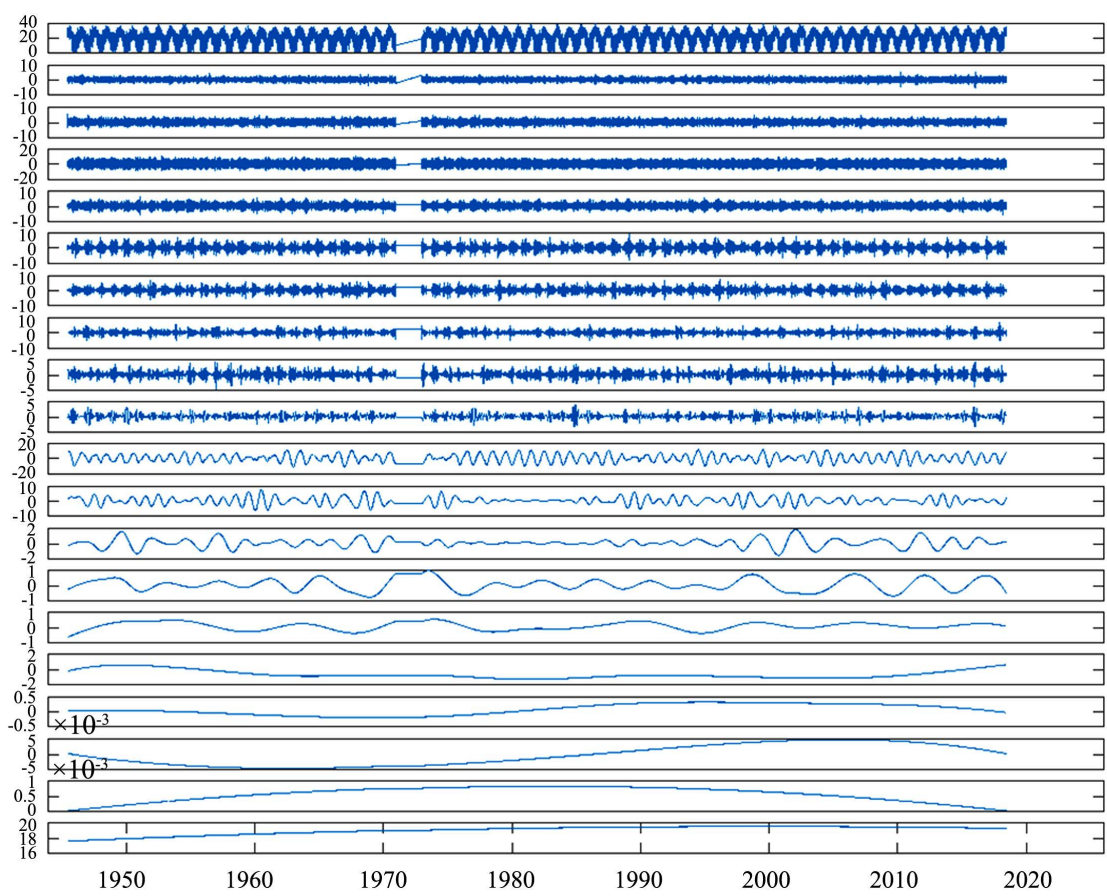

Figure 1. The Air Temperature time series and EEMD 19 IMF modes for Charleston. Top Panel is the hourly time series ranging from $0^{\circ} \mathrm{C}$ to $40^{\circ} \mathrm{C}$. Vertical axes are amplitudes in ${ }^{\circ} \mathrm{C}$, horizontal axes designate decades.

We find 18 Oscillatory EEMD-IMF modes and the $19^{\text {th }}$ mode, the overall gravest mode, is the total time series "trend" [3]. The modes are stacked top to bottom in order of increasing period (and the range in temperatures in ${ }^{\circ} \mathrm{C}$ ). IMF Mode 1 is $2-3$ hourly $\left(+/-3^{\circ} \mathrm{C}\right)$, Mode 2 is 6 -hourly $\left(+/-5^{\circ} \mathrm{C}\right), 3$ is 12 hourly $\left(+/-10^{\circ} \mathrm{C}\right)$ and 4 is 24 hourly $\left(+/-10^{\circ} \mathrm{C}\right)$. Mode 5 is $2-4$ days $\left(+/-8^{\circ} \mathrm{C}\right), 6$ is $5-10$ days $\left(+/-8^{\circ} \mathrm{C}\right), 7$ is $1-2$ monthly $\left(+/-8^{\circ} \mathrm{C}\right), 8$ is 3 monthly $\left(+/-8^{\circ} \mathrm{C}\right)$ and 9 is $\sim 6$ monthly $\left(+/-3^{\circ} \mathrm{C}\right)$. Mode 10 is yearly $\left(+/-15^{\circ} \mathrm{C}\right), 11$ is $2-3$ years $\left(+/-8^{\circ} \mathrm{C}\right), 12$ is 3 - 5 years $\left(+/-2^{\circ} \mathrm{C}\right)$ and 13 is $5-7$ years $\left(+/-2^{\circ} \mathrm{C}\right)$. Mode 14 is $10-12$ years $\left(+/-2^{\circ} \mathrm{C}\right), 15$ is $\sim 20-22$ years $\left(+/-2^{\circ} \mathrm{C}\right), 16$ is $32-34$ years $\left(+/-0.5^{\circ} \mathrm{C}\right), 17$ is $\sim 65$ - 70 years $\left(+/-0.5^{\circ} \mathrm{C}\right)$, and 18 is $\sim 120$ years $\left(+/-0.5^{\circ} \mathrm{C}\right)$ and displays the first half of a possible 120 year oscillation. Mode 19 is the 77 -year record length trend and shows a $2^{\circ} \mathrm{C}\left(3.6^{\circ} \mathrm{F}\right)$ or $0.26^{\circ} \mathrm{C} /$ decade rise in atmospheric temperature at Charleston. For the purposes of this discussion, the wind record at Charleston (not shown) displays the same intrinsic mode function decomposition of 19 modes over the 125-year period. However, IMF 4 is broader, extending from 22 to 25 hours and the overall trend in wind speeds is zero, so the flat trend says there has not been an increase or decrease in wind speeds.

From Figure 1, the question arises: are there naturally occurring phenomena which display these 19 internal, intrinsic modes of variability? To review: 1) at the high frequency end of the spectrum, in the atmospheric, the hourly data, from shorter periods of hours to days, reveal the presence of thermals, fronts, squalls, thunderstorms, diurnal variability, mesoscale events, high and low pressure systems, mid-latitude cyclones, tropical cyclones; 2) extending to planetary 
waves the order of a month; 3 ) the Madden-Julian Oscillation of $\sim 2$ months; 4) on to 3 and 6 month seasons; 5) annual and inter-annual; 6) multi-year g) 10 12 year ; 7) 21 - 23 year Solar Cycles; 8) the 60 - 65 year Meridional Circulation Cycle; and 9) the 140 year Global Thermohaline Cycle. Cycles (1) and (9) affect the North Atlantic Ocean Basin scale wind-fields such as the North Atlantic Oscillation (NAO). Next, we consider kinematical descriptors of the wind-field.

In Figure 2, we see the water level hourly time series and EEMD IMFs for Charleston SC (Top of the Panel is the 73 year hourly time series) ranging from 0 meters $(\mathrm{m})$ to $4 \mathrm{~m}$. It is of note that the tidal range at Charleston is generally less than $2.5 \mathrm{~m}$ but one event in 1990 upped the overall range record and we chose not to clip the data point. There are 18 oscillatory EEMD IMF modes and the $19^{\text {th }}$ gravest mode, the trend. The modes are stacked top to bottom in order of increasing period (and the range in amplitudes). Mode 1 is 3 - 6 hourly, higher harmonics of the M2 Tide $(+/-1.0 \mathrm{~m})$. Mode 2 is the Semi-Diurnal M2 12.42 hourly Tide $(+/-2.0 \mathrm{~m})$, Mode 3 is the inertial signal at $\sim 18$ hours $(+/-0.5 \mathrm{~m})$ and Mode 4 is the Diurnal S2 or 24 hourly $(+/-0.5 \mathrm{~m})$. Modes 5 and 6 are atmospheric wind driven $2-4$ day $(+/-0.5 \mathrm{~m})$ and $5-7$ day $(+/-0.5 \mathrm{~m})$, signatures respectively. Mode 7 is 14 days or the fortnightly $(+/-0.5 \mathrm{~m})$ tide. Mode 8 is 3 -monthly $(+/-0.2 \mathrm{~m})$ and Mode 9 is 6 -monthly $(+/-0.2 \mathrm{~m})$. Mode 10 is annual $(+/-0.2 \mathrm{~m})$. Mode 11 is $2-3$ years $(+/-0.2 \mathrm{~m})$, Mode 12 is $3-5$ years $(+/-0.05$ $\mathrm{m})$, and Mode 13 is $5-7$ years $(+/-0.05 \mathrm{~m})$. Mode 14 is 11 years $(+/-0.05 \mathrm{~m})$, Mode 15 is 22 years $(+/-0.02 \mathrm{~m}), 16$ is 33 years $(+/-0.00002 \mathrm{~m}), 17$ is 70 years $(+/-0.00005 \mathrm{~m})$, and 18 is the first half cycle of a 140 year mode $(+/-0.00004 \mathrm{~m})$.

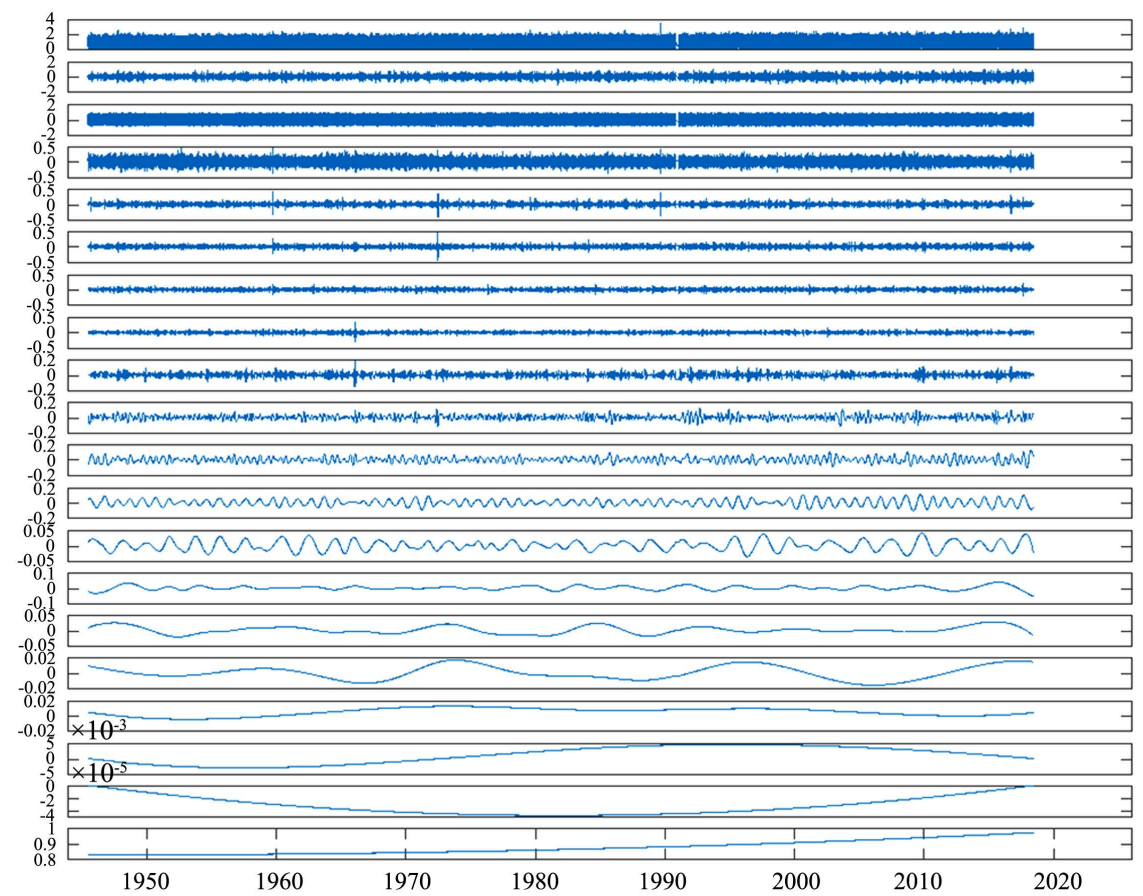

Figure 2. Hourly water level data at Charleston SC dating from 07/01/1945 through $06 / 30 / 2018$. The original time series is in the top panel. Vertical axes are in units of meters, horizontal axes are decades. 
Mode 19 is the 73-year (record length) trend and shows a water level rise of $0.027 \mathrm{~m}$ or $0.365 \mathrm{~cm} / \mathrm{yr}$. We note that IMF 10 is the "annual" mode and is relatively stable with $+/-$ amplitudes of less than $15 \mathrm{~cm}$. However, in the annually averaged plot (Figure 3(a)) there is a large jump of $25 \mathrm{~cm}$, which occurs in the 1940's-1950. The question is, where is this jump reflected in Figure 4? The answer is, in the lower frequency, IMFs of $13-18$, all of which are in a quasi-decade long upward swing in amplitude.

Figure 3 is the time series of yearly average hourly water levels for Charleston. As seen, one to two year differences of up to $25 \mathrm{~cm}$ of annual averages are evident. During the 1920s and the mid-1930s there was an apparent relative low in the North Atlantic Ocean Basin. These decadal to multi-decadal relative drops and rises in the time series display high amplitude, $+/-5 \mathrm{~cm}$ to $+/-20 \mathrm{~cm}, 1$ to 2 -year variations. A yearly average, by definition, contains all of the internal EEMD-IMFs of variability for that particular year.

Charleston, SC Yearly Average Mean Sea Level $1921-2004$

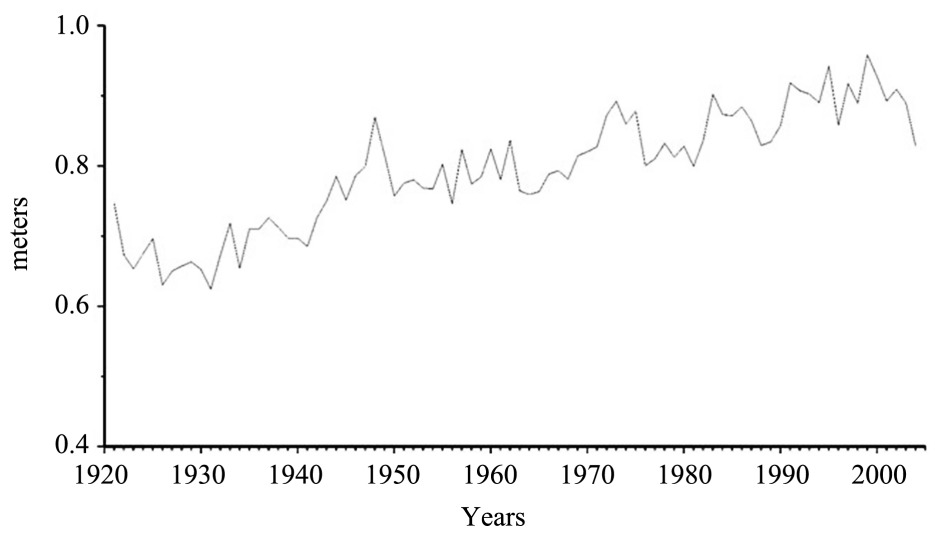

Figure 3. Annual (yearly) average hourly water level data from Charleston.

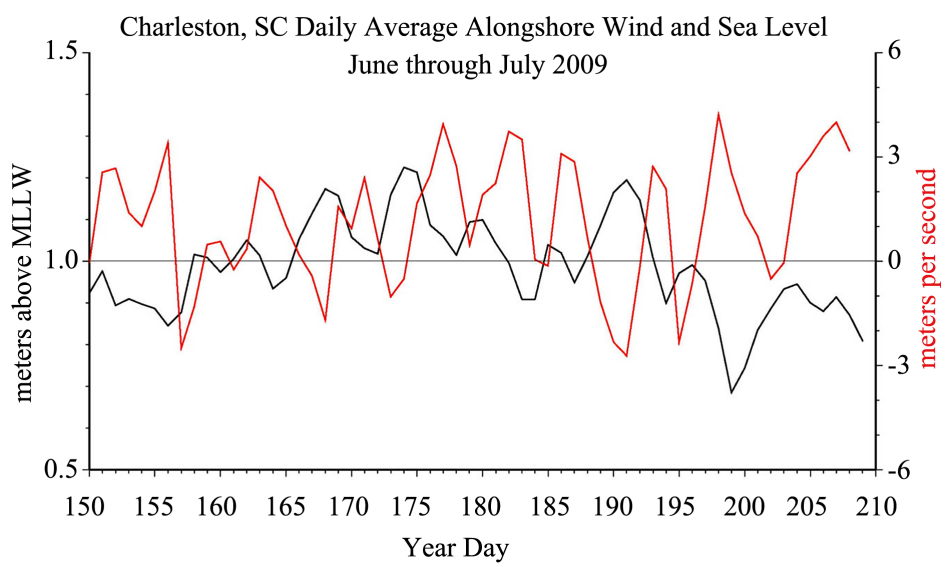

Figure 4. Daily averaged alongshore winds and coastal water levels at Charleston. Wind components positive (towards the northeast) cause water levels to drop (go negative). Winds towards the southwest (negative) cause water levels to rise (become positive). Time along the horizontal axis is in year-days (Julian). 
On an hourly basis, water levels at Charleston not only reflect the astronomical tides but the alongshore component of the wind. If one averages the hourly alongshore components of the winds and water levels at Charleston, then the 60 -day plot shown in Figure 4 results. Basically when the alongshore component of the wind blows towards the northeast, then water level drops at the coast and when the alongshore component winds blows down the coast to the southwest, water level rises at the coast. There is the caveat of an 8-hour lag in the non-tidal response, as first reported in [5]. If the winds blow with the coast to the left (right) coastal sea level will fall (rise). This is a mechanical response and carries through from hours to days to weeks to months. Figure 5 demonstrates the tight coupling between the alongshore winds and water levels at Charleston. A moving correlation [6] between the two monthly averaged time series over a 62-year period (Figure 5) shows that the coupling is very tight.

Figure 6(a) and Figure 6(b) reveal the axis orientations, the primary directions of particle motions for different bandwidths, the stability of and repeatability of the motions, and the coherency of the horizontally polarized $+\mathrm{u}\left(135^{\circ}\right.$ east of north), $+\mathrm{v}$ ( $45^{\circ}$ east of north) components of motion of the entire 2003 time series of hourly wind data. In this decomposition, we employ the $\mathrm{u}, \mathrm{v}$ directions from the harvested NCEI data sets. In 6a the horizontal axis extends from 0.3 cycles/hour to $1.142\left(10^{-5}\right) \mathrm{cy} / \mathrm{hr}$ (3 hours to 1 year) and Figure 6(b) extends from $0.04 \mathrm{cy} / \mathrm{hr}$ to $1.142\left(10^{-5}\right) \mathrm{cy} / \mathrm{hr}$ (25 hours to 1 year) thereby stretching the axis and making it more readable. We added color in Figure 6(a) for visual relief. However, there are caveats in considering a 12-month period decomposition

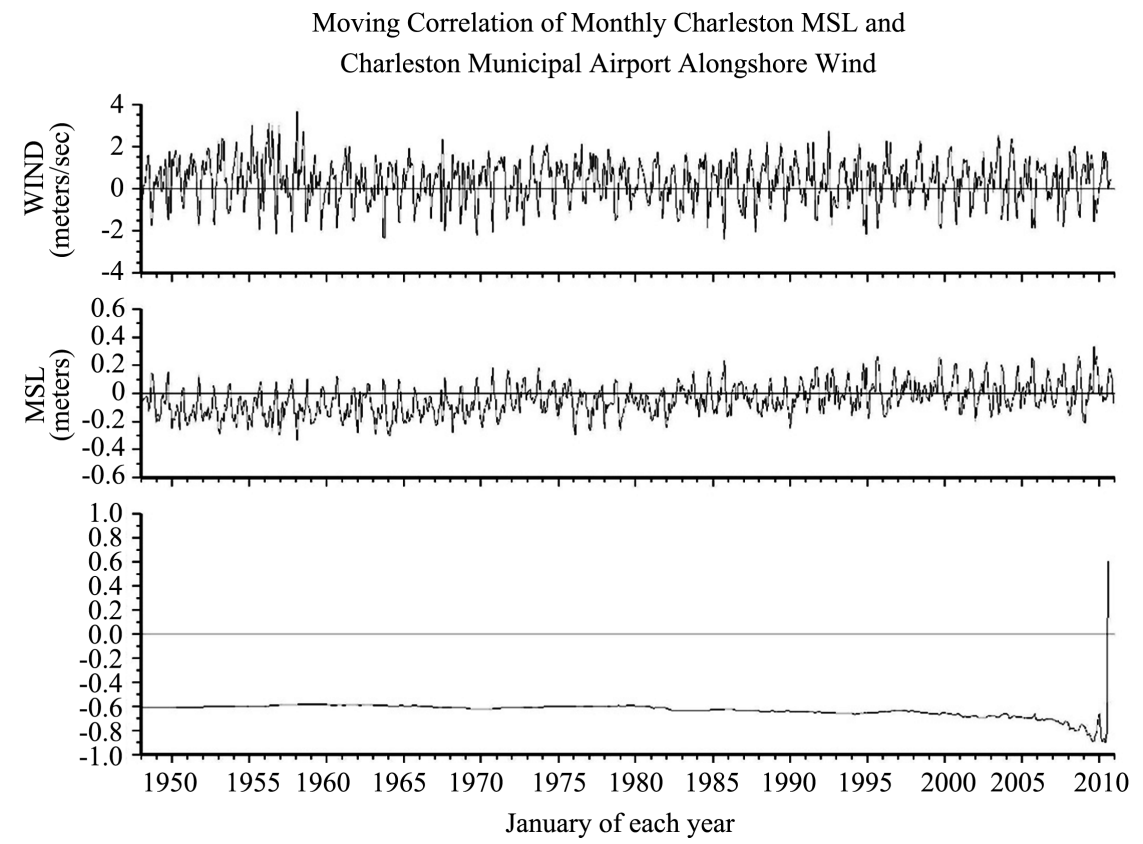

Figure 5. Upper Panel, alongshore wind speeds (positive is towards the northeast, negative is towards the southwest). Middle Panel, water level rises (upwards) and falls (downwards) at Charleston. Lower Panel, is the moving correlation coefficient, locked in at -0.6 , between coastal alongshore winds and water levels at Charleston. 

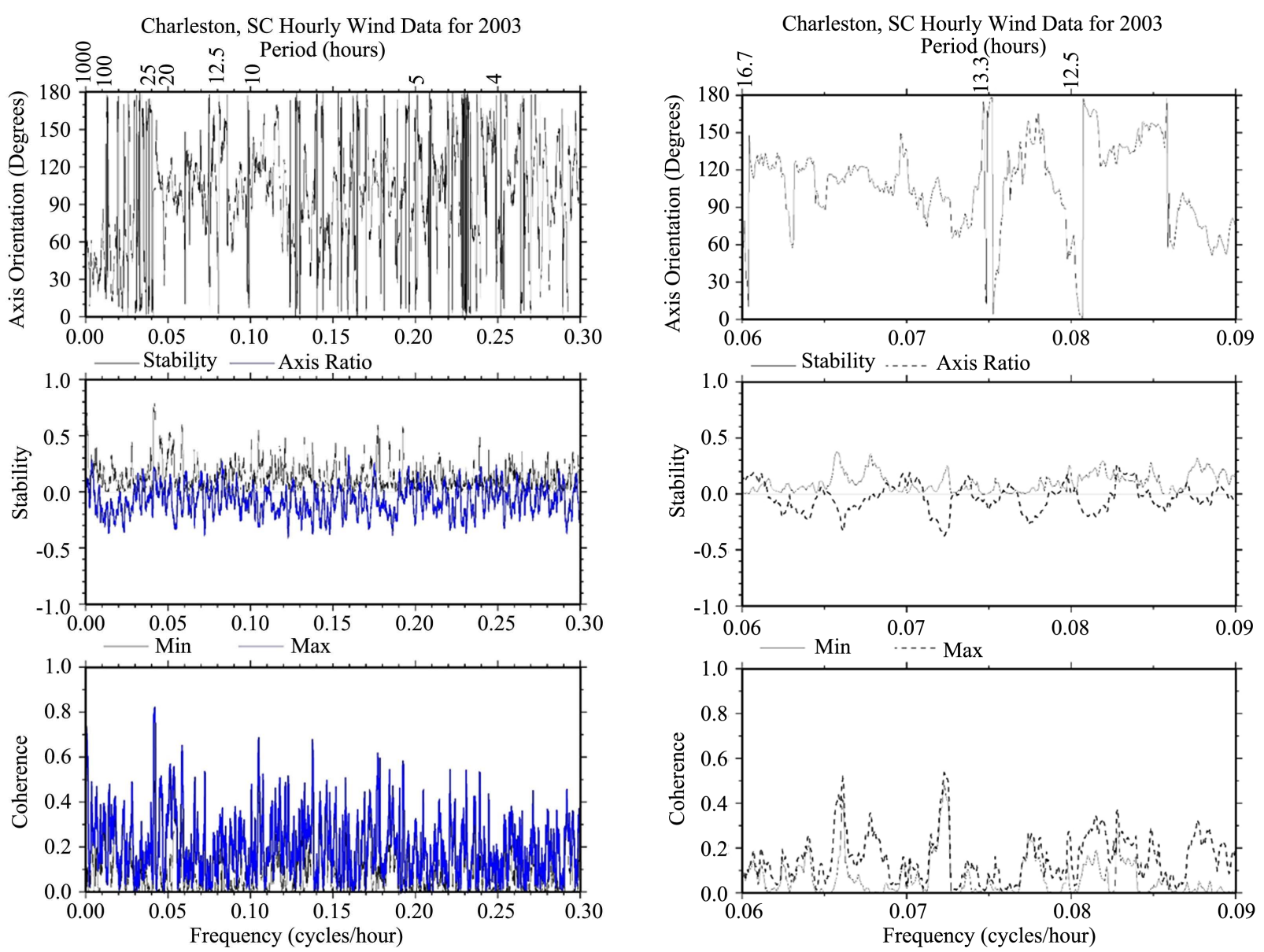

(a)

(b)

Figure 6. Hodograph-Kinematic Descriptors of Charleston 2003 hourly wind data. (a) Left panel is 0.3 cycles/hour to $1.142\left(10^{-5}\right)$ cy/hr ( 3 hours to 1 year). Particle motions between 3 and 12 hours are aligned along the coast and are generally not stable nor coherent, save for signals at 6,8,20 and 24 hours which are coherent, stable, and aligned perpendicular to the coast; (b) Right panel extends from $0.04 \mathrm{cy} / \mathrm{hr}$ to $1.142\left(10^{-5}\right) \mathrm{cy} / \mathrm{hr}$ (25 hours to 1 year). Motions at 25,50 and 75 hours are coherent, stable and aligned along the coast. Coherent, stable motions of $4-8$ days and 3 months are aligned perpendicular to the coast.

using a hodograph descriptor approach. As discussed in [6] [7] there are significant differences in the seasons of winter versus those in summer, so mashing them together, as the plots in Figure 6(a) and Figure 6(b) show, can create a confusing picture. Therefore, we break the time series up into winter and summer segments to better elucidate the descriptors. To do this we choose the summer period of June through August 2003. The winter period is December 2002 through February 2003.

Figure 7(a), Figure 7(b), present the hodograph descriptors of the u, v particle motions during the summer and winter periods. During the summer, June-August 2003, motions with periods less than the quasi-diurnal sea breeze or Coastal Frontal System (CFS), ranging from 22 - 26 hours, centered about 24 hours, and for the inertial period of 22.1 hours are not highly coherent. The Inertial Oscillation (IO) shows up as a weakly coherent clockwise rotating elongated ellipse while the CFS is highly coherent and stable, circular and counterclockwise 


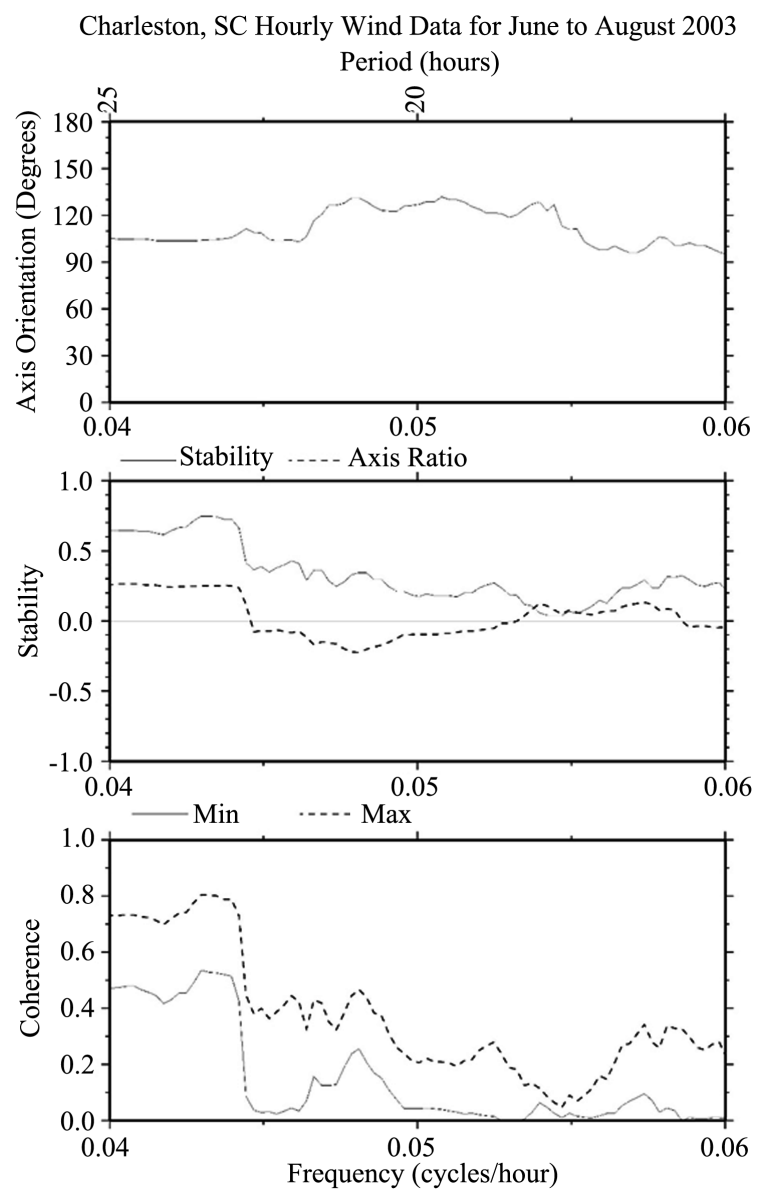

(a)
Charleston, SC Hourly Wind Data for December 2002 to February 2003 Period (hours)
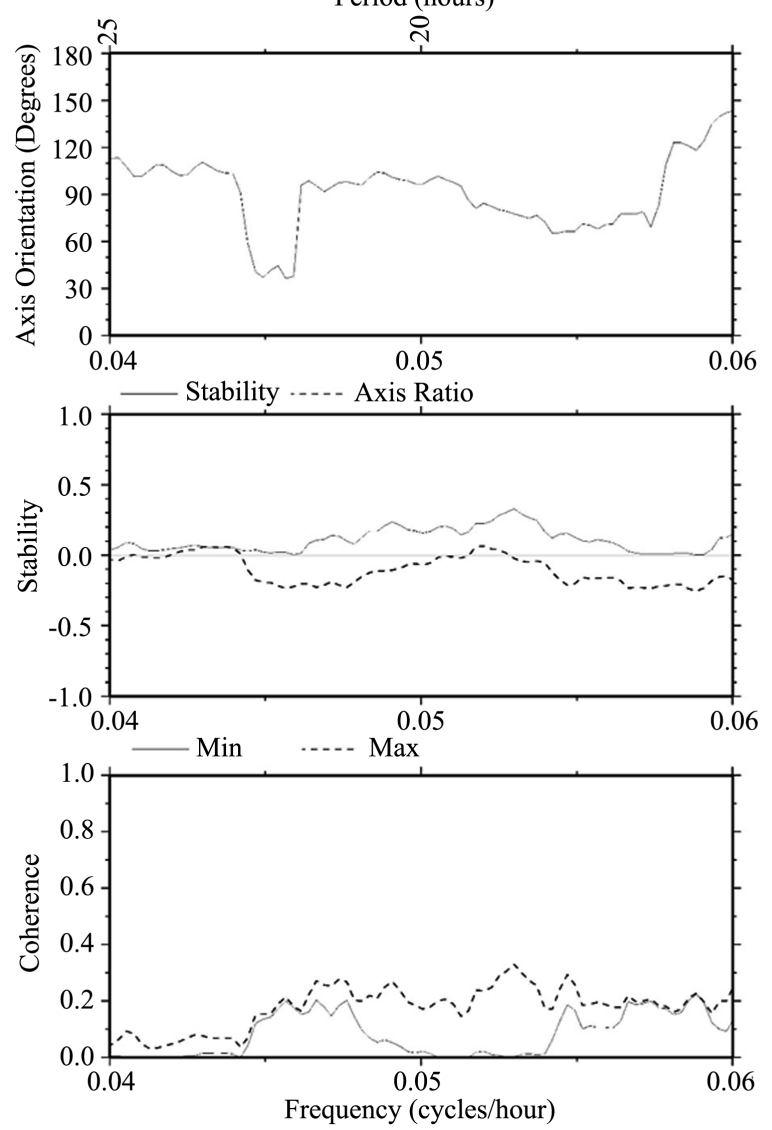

(b)

Figure 7. Kinematical descriptors of axis orientation, stability and coherency of: (a) summertime (left panel) versus (b) wintertime (right panel) motions for 1 hour to 2-hour period of the Charleston wind field motions.

rotating. It is of note that for the winter decomposition we included December 2002 and January-February 2003 hourly data, so 3-months in length (right panel) and the June-August 2003, 3-month summer period (left panel). The IO at 22 hours and the CFS, extending from $22-26$ hours, centered about 24 hours, both are aligned $15^{\circ}$ west of north in both summer and winter. Recall that these bands sit within the broader band of the IO out to 2 days, which occupies some $30 \%$ of the total KED of the wind-field at Charleston. Within the CFS, the particle motions during the summer are very coherent and stable, thus repeatable from day to day, are counterclockwise rotating about elongated ellipses nominally aligned approximately perpendicular to the coastline. However, this is not the situation during the winter months of December-February where the CFS displays low stability and low coherence in $\mathrm{u}, \mathrm{v}$ particle motions.

While the CFS exists, it is intermittent, with incoherent unstable motions. In Figure 8(a) and Figure 8(b), we show a NOAA GOES visible satellite image and a percent (\%) of onshore-offshore penetration of the CFS during the summertime produced by assessing twice daily images of the GOES imagery downloaded at North Carolina State University via its HRPT satellite station atop Jordan Hall 


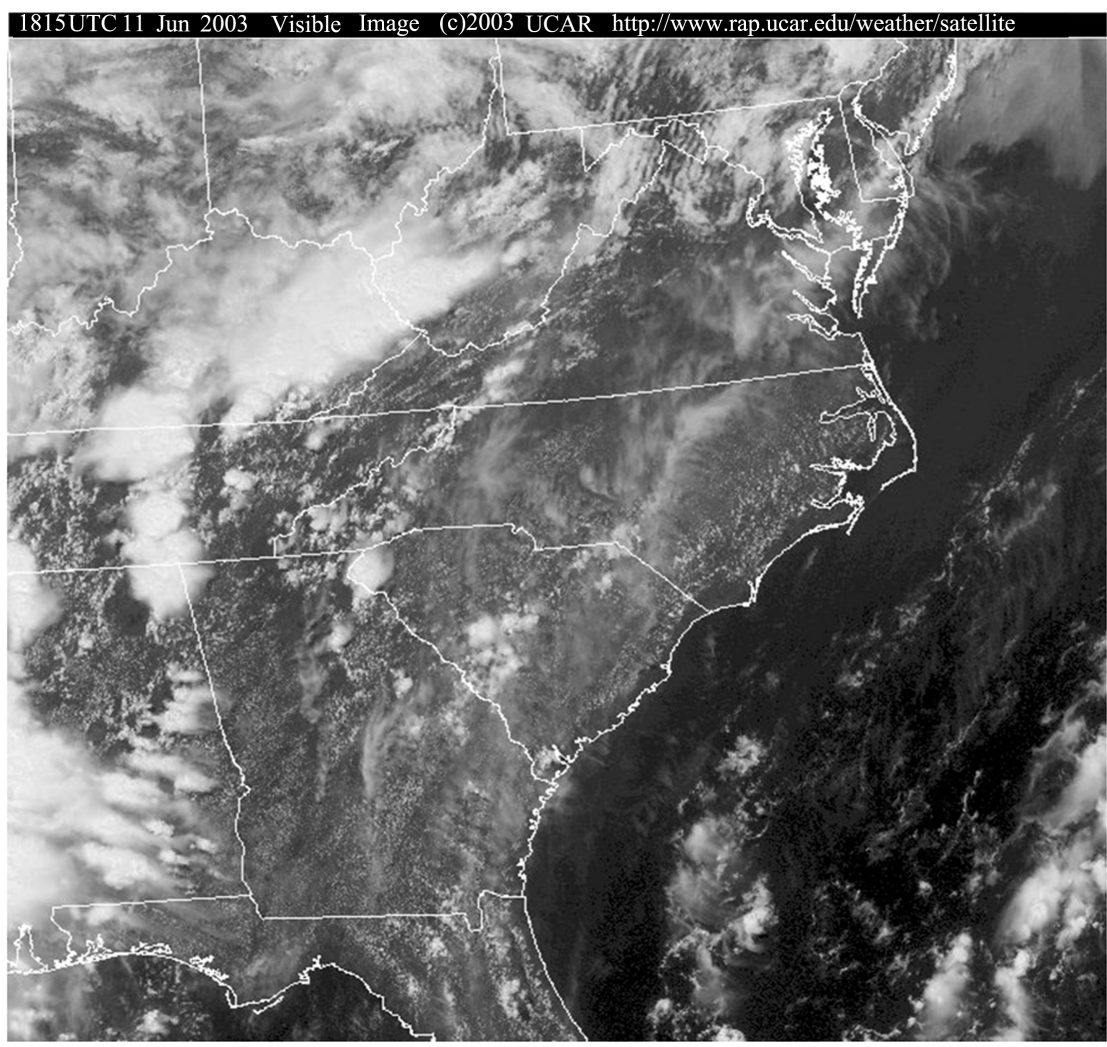

(a)

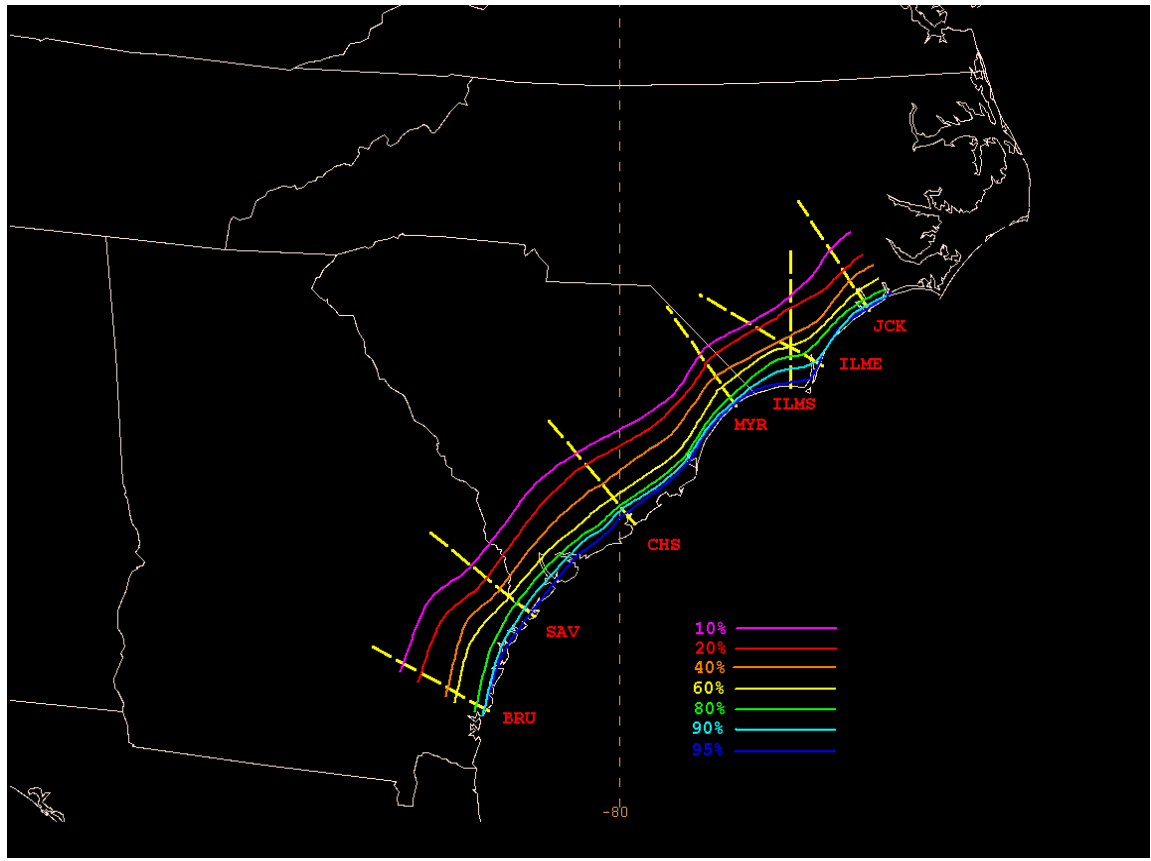

(b)

Figure 8. (a) Left panel is a NOAA GOES satellite visible image of the CFS; (b) Right panel is the \% probability of onshore penetration of the CFS in the Southeast U.S in 1998-99.

in 1998-99. As is evident, the CFS is very coherent in the alongshore direction and can penetrate great distances both onshore and offshore (not shown). 
The IO is weak to non-existent during the winter period in the Charleston wind-field. It is of note that [9] found that winter cold fronts that pass through the southeastern U.S., and as they do, they excite inertial currents in the coastal ocean from the surface downward throughout the entire water column. That study presented observational current meter data collected offshore of Charleston, band-passed the data to focus on the inertial period and found a robust downward propagating IO signal. The study also included the solution to a closed form numerical model that theoretically confirmed the observations. The study determined that fast-moving atmospheric winter cold fronts, moving from west to east or from land to offshore, impulsively force the coastal ocean at the surface, which responds by propagating inertial waves from the surface downward throughout the water column. That study was the first of its kind at that time and was a pioneering effort.

In Figure 9 the hodograph descriptor plots of $\mathrm{u}, \mathrm{v}$ particle motions of Charleston atmospheric winds during the summer and winter periods are presented for the entire 3-month periods of observations. The axis orientation, stability
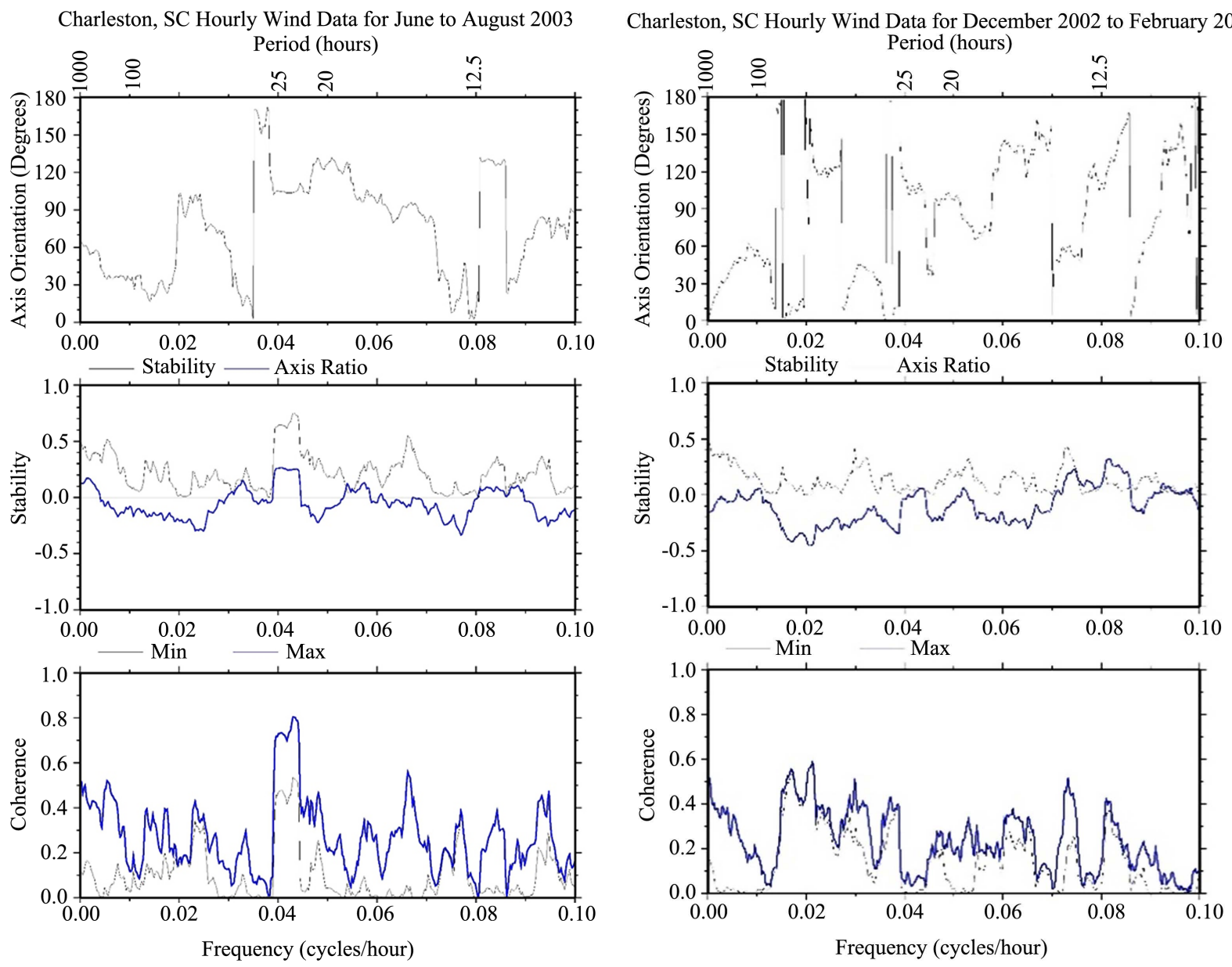

(a)

(b)

Figure 9. Hodograph Descriptors from 0.1 to 0.001 cycles per hour during: (a) left panel Summertime, June-August 2003; (b) right panel Wintertime, December 2002-February 2003. 
and coherency of $\mathrm{u}, \mathrm{v}$ particle motions are shown. For the summer period (left panel) across the meso-synoptic band of 2 - 10 days, centered about 4 - 6 days, the motions are clockwise rotating, about stable ellipse oriented with their major axes about $40^{\circ}$ east of north thus approximately aligned with the coastal orientation. The signal at $\sim 2$ days is reasonably strong. It may be an extension of the CFS buried within the alongshore mean flow associated with the Azores-Bermuda High Pressure system present in the SE during the late spring, summer and early fall. In Figure 9(b) (right panel), the winter-time meso-synoptic scale particle motions tend to be relatively unstable, non-repeatable, rectilinear, so straight-line back and forth, aligned between $40^{\circ}$ and $60^{\circ}$ east of north, so along the coastline. These are associated with the passages of wintertime low-pressure storm systems accompanied by drops in atmospheric temperatures, so EEMD-IMFs 5, 6 .

In Figure 10(a), we consider the annual precipitation along the Charleston coast over a 100-year period. The year-to-year variability ranges from 3 to 27 inches, over annual totals of 39 to 69 inches. The mean of the time series is nominally about 52 inches/year. However, the annual to bi-annual and even decadal variability is considerable. In Figure 10(b), we present the 110 year record of Carolina coastal precipitation in terms of 50\% median ranges, upper $(23.5 \%)$ and lower (25\%) quartiles and outliers. These are the Box-Whisker-Outlier (BWO) plots of [7]. The uppermost outliers are defined as $1.5 \%$ above the highest values for that month as a function of year. The April, May, November and December outliers are related to the passages of Mid-Latitude or Extra-Tropical Cyclones while the June-October outliers reflect the passages of Tropical Cyclones. These storm events are reflected in the annual variability in precipitation shown in Figure 10(a). The point made here is that individual atmospheric storm events can drop significant amounts of rain in short periods of time and thus render the term "mean" in precipitation to be a mathematical artifact and thus physically meaningless, in non-arithmetic terms.

Next we present wind and wave BWO plots (Figure 11(a) and Figure 11(b)) respectively, and their spectral density analogues (Figure 12(a) and Figure 12(b), respectively. This approach was used previously in [10].

The annual distributions of wind speeds and the wave amplitude distributions are in good agreement with each other. However, it is clear that wave amplitudes are not only a reflection of the local generation of waves ("sea") but also carry the arrival of waves which have been generated elsewhere ("swell") and which have propagated into the area of the buoy and thus contribute to the overall wave amplitude measurements. Curiously, the spectral distributions of the wind speeds (Figure 12(a)) and that of the wave amplitudes (Figure 12(b)) appear to be lognormal in the winds versus exponential in the waves. The reasons for this are unknown and this could be a universal finding, as the literature contains no reference to these results and thus these may be original findings. Momentum inputs from atmospheric winds non-linearly transfer into wave momenta and sea and swell likely coalesce non-linearly. 


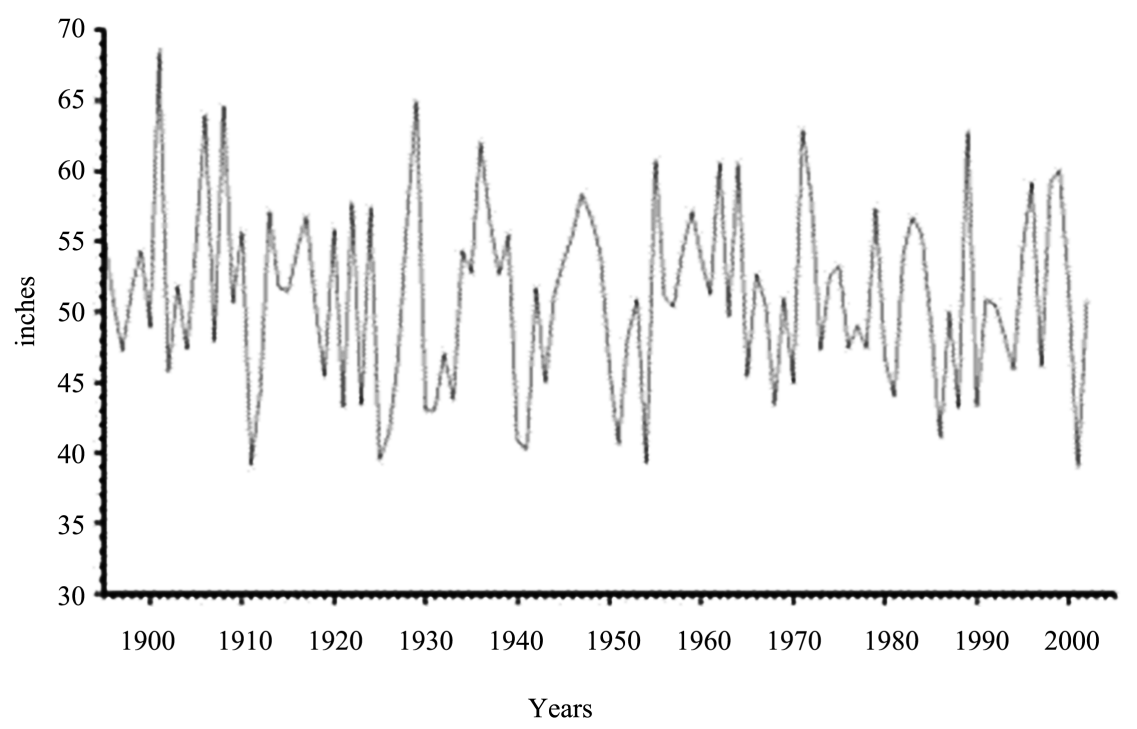

(a)

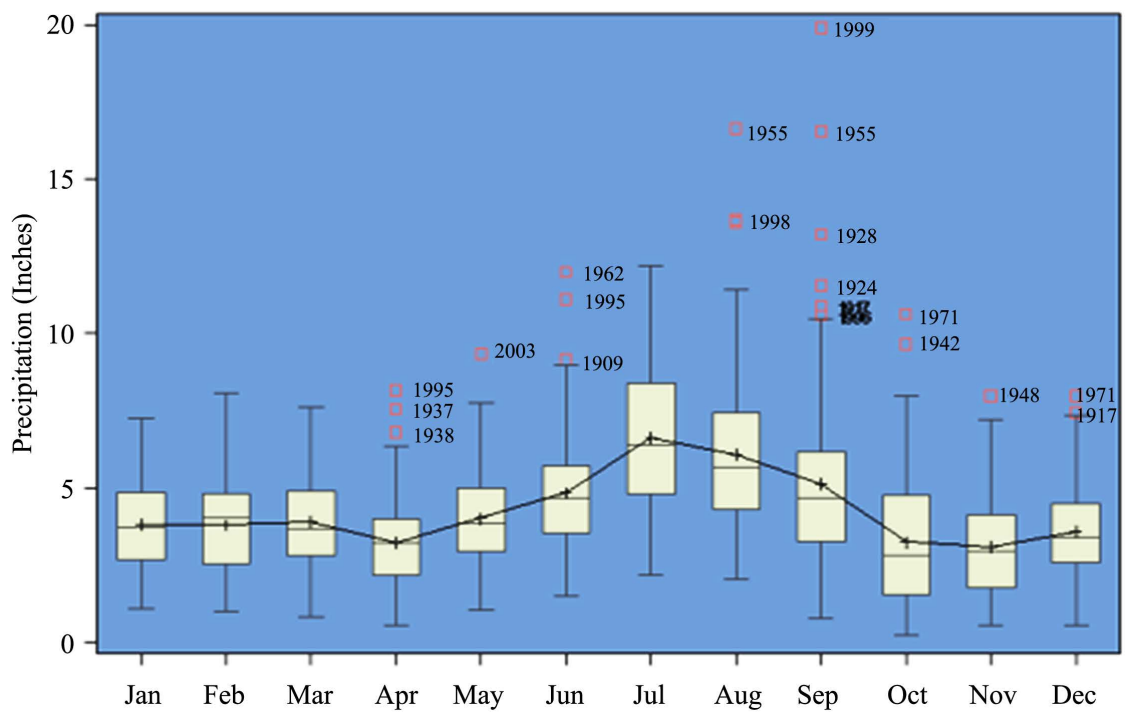

(b)

Figure 10. (a) Left panel is the annual total precipitation along the Charleston coast over a 110-year period; (b) Right panel are 50\% Medians, Lower 25\% Quartile and Upper $23.5 \%$ of relative values (Whiskers) and $1.5 \%$ relative upper values (Outliers) of Precipitation in the Charleston region by Month.

Next, we create a prognostic capability for waves directly from winds and prior waves measured at NDBC 41004 . The approach is different from the conventional approaches of forecasting waves such as the NOAA Wave-Watch: https://polar.ncep.noaa.gov/waves/, which is numerical model based. Our development simply utilizes winds and waves from a NOAA Buoy. We demonstrate the statistical model via data collected at NDBC 41004. The statistical forecast, from 1 to 24 hours is conducted via a transfer function regression prediction [7] of the form $\mathrm{H}(\mathrm{t})=\ldots+\ldots \mathrm{W}(\mathrm{t})+\ldots \mathrm{W}(\mathrm{t}-1)+\ldots+\ldots \mathrm{W}(\mathrm{t}-\mathrm{p})+$ _ $\mathrm{H}(\mathrm{t}-1)+\ldots \mathrm{H}(\mathrm{t}-2)+\ldots+\ldots \mathrm{H}(\mathrm{t}-\mathrm{q})$, where $\mathrm{H}$ is wave height, $\mathrm{t}$ is time, 


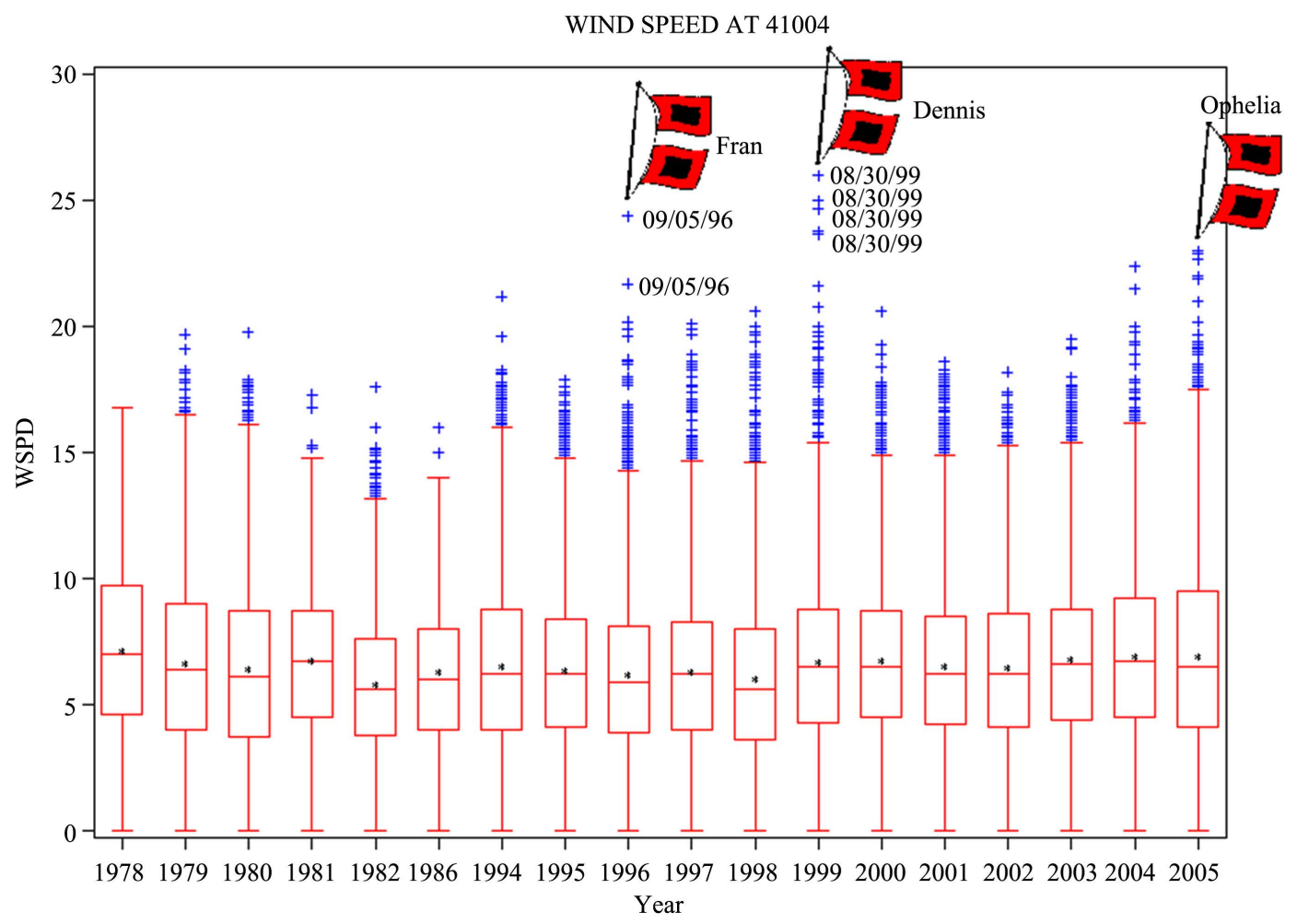

(a)

WAVE HEIGHT AT 41004

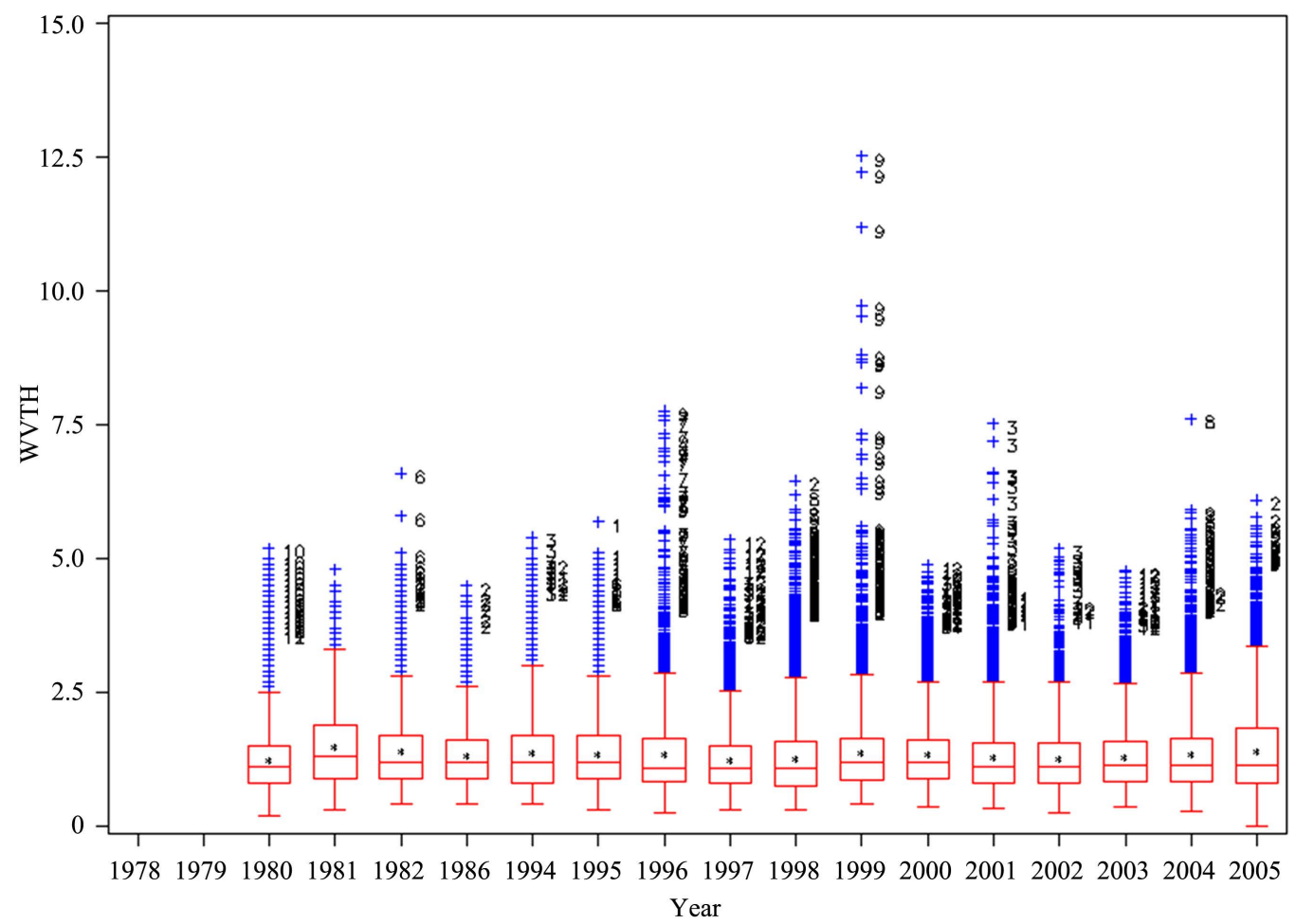

(b)

Figure 11. BWOs at NDBO 41004 off Charleston from 1978-2005 for: (a) left panel wind speeds; and (b) right panel, wave amplitudes BWOs of wave amplitudes. 


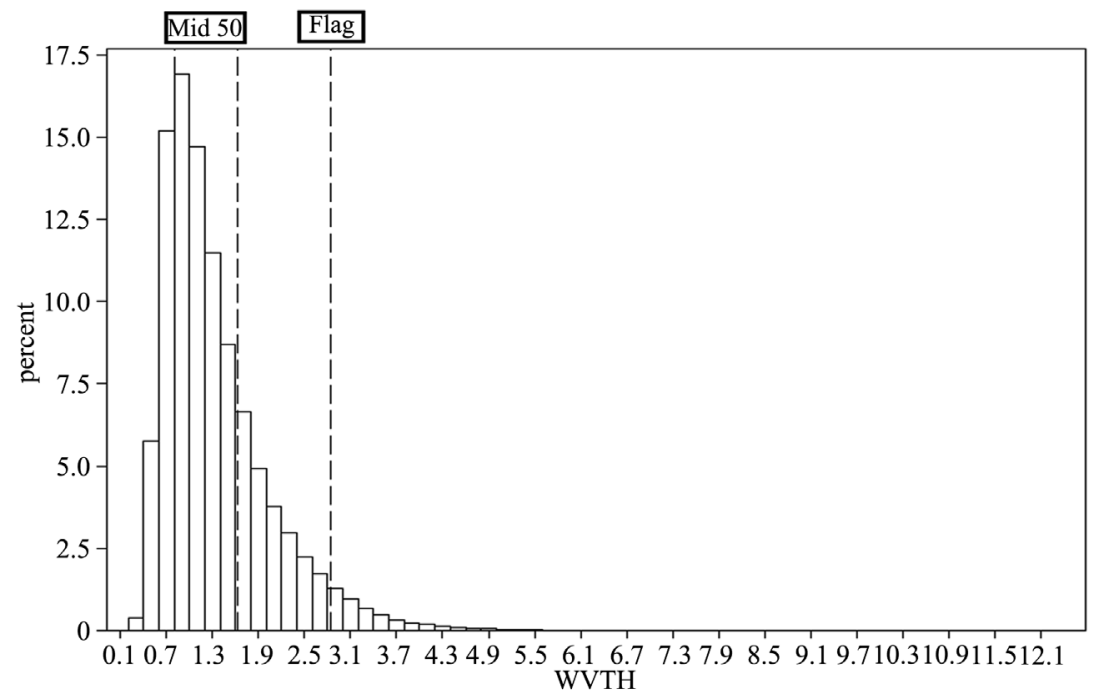

(a)

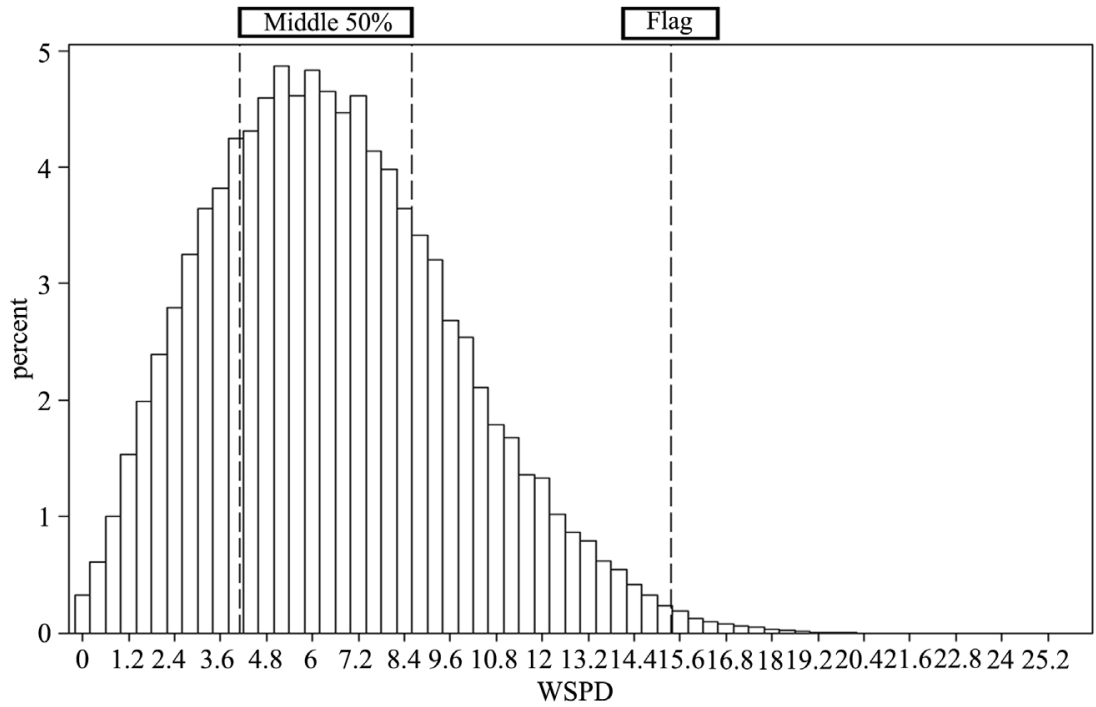

(b)

Figure 12. The Spectral Density of: (a) winds in left panel; and (b) waves in the right panel measured at the NOAA Marine Buoy NDBC 41004 off Charleston from 1978-2005. The distributions are shown as a percent of the total height in units of percent of meters as a function of wind amplitudes (a) left panel and wave heights (b) right panel.

and $\mathrm{W}$ is wind speed. We plot the forecasted relationships in Figure 13(a). The hourly $\mathrm{R}^{2}$ "goodness" of the forecast [7] from 1 to 24 hours forward is shown in Figure 13(b). The red dots employ past waves only to predict waves while the blue dots result from winds and prior waves. The forecasts are quite good for about 10 hours ahead and updating them every hour would yield a statistically solid forecast capability. We have tested this transfer function on NDBC buoys in North Atlantic and North Pacific Ocean Basin and Great Lakes waters and it works uniformly well. That implies a reliable data based forecast of wave amplitudes out to 10 hours at all NDBC sites and could be implemented as a NOAA tool. This tool could be of great benefit to the boating and fishing communities. 


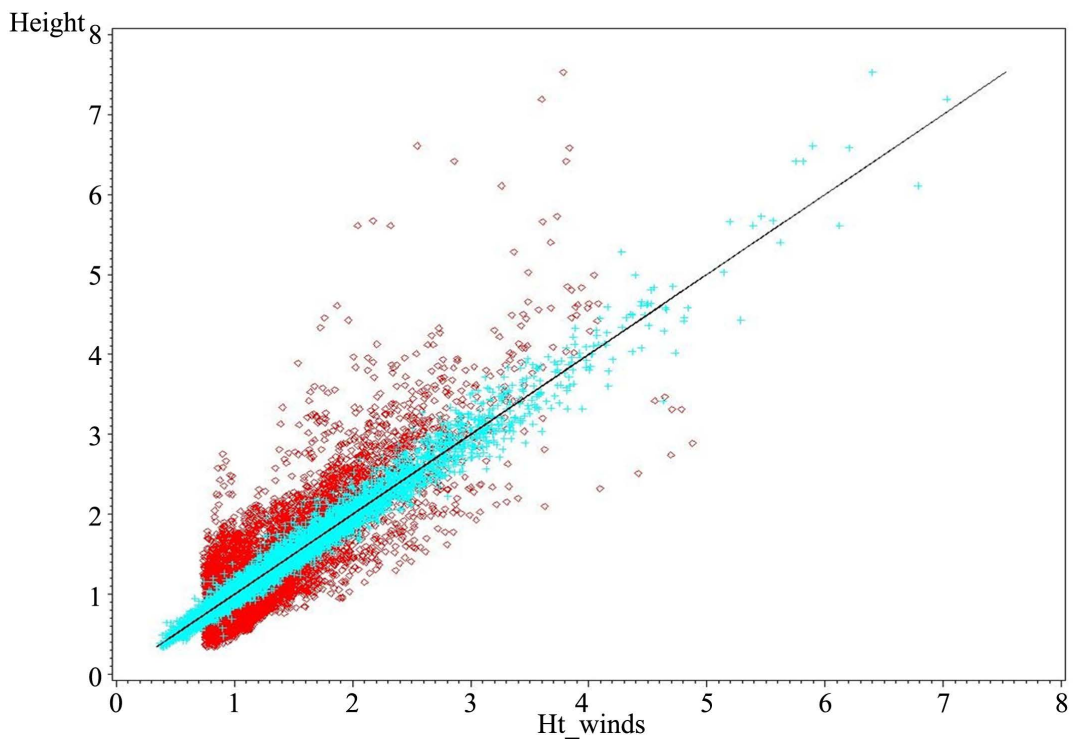

(a)

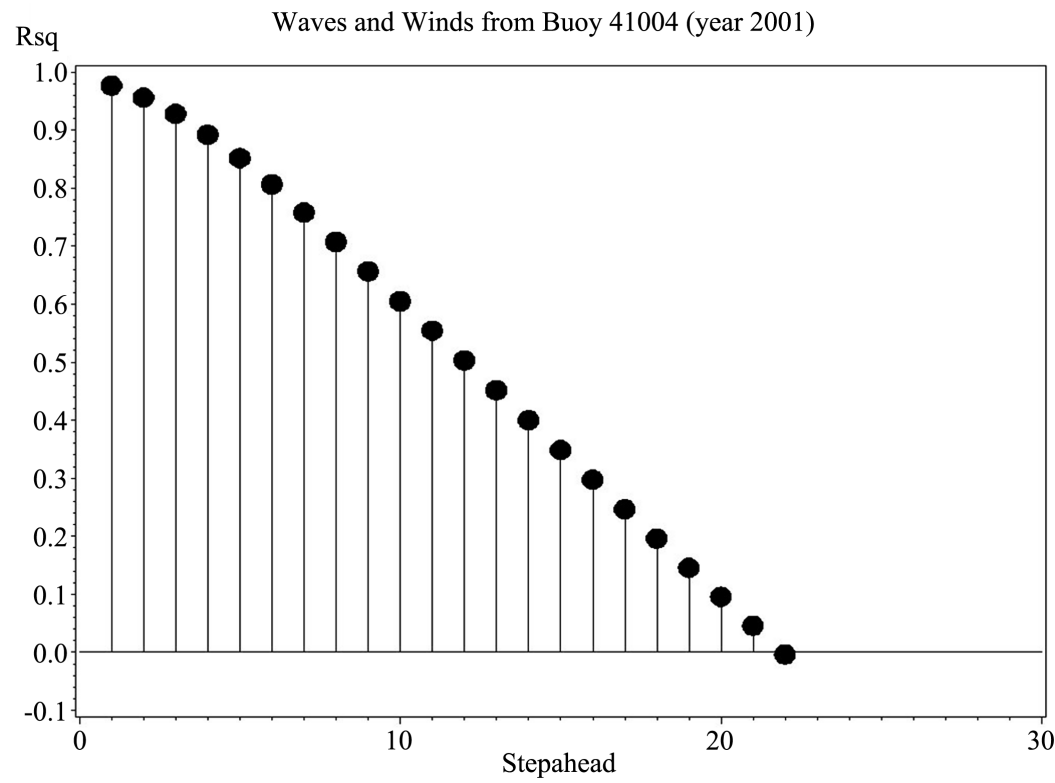

(b)

Figure 13. (a) Left panel is a prognostic forecast of waves from 1 to 24 hours; (b) Right panel is the $\mathrm{R}^{2}$ of hourly forecasts of Winds (red) and Waves from Winds \& Waves (blue).

\section{Discussion and Conclusions}

We show that atmospheric temperature, wind and sea-level variability at Charleston SC reflect a suite of nonlinear and non-stationary phenomena that are individually identifiable and are occurring simultaneously. We propose that the weather to climate spectra in the atmosphere actually constitute an overlapping continuum, with shorter period oscillations riding atop longer period oscillations and then atop overall record length trends. Inertial, diurnal and CFS motions extending out to 2 days occupy up to $30 \%$ of Kinetic Energy Densities and are stable motions during the summer but not so during the winter. The meso to 
synoptic scale band band of 2 - 10 days occupies some $50 \%$ of the KED year annually. We conclude that the Coastal Frontal System is well developed during the summer but not so in the winter. Coastal wind inertial oscillations are weakly developed in the summer but not so in the winter. Winds and waves in the Charleston coastal ocean are well correlated and a statistical method is developed which demonstrates that by employing prior wind speeds and prior wave amplitudes from a NOAA NDBC Marine Buoy, one can predict wave amplitudes. This statistical data-based model predicts wave amplitudes at a relatively high degree of predictability from 1 out to 10 hours, automatically updated every hour. Precipitation is shown to be highly variable and dependent on atmospheric meso-scale atmospheric storm activity. Moreover, we demonstrate that annualized precipitation amounts across a coastal region, while mathematically tractable, are physically meaningless from year to year other than to show the degree of "storminess" from year to year.

The World Meteorological Organization (WMO) defines weather and climate in general and at a specific location <https://public.wmo.int/en> as: 1) "The state of the atmosphere at a given time and location. Weather is driven by a diverse set of naturally occurring phenomena, especially air pressure, temperature, and moisture differences between one place and another, most of which occur in the troposphere"; and 2) "Climate in a narrow sense is usually defined as the "average weather," or more rigorously, as the statistical description in terms of the mean and variability of relevant quantities over a period of time ranging from months to thousands or millions of years. The classical period is 30 years, as defined by the World Meteorological Organization (WMO). These quantities are most often surface variables such as temperature, precipitation, and wind. Climate in a wider sense is the state, including a statistical description, of the climate system". In our decompositions of coastal atmospheric temperatures, winds and precipitation and coastal sea level, we have uncovered hourly to daily to weekly to seasonal to annual to multi-annual to decadal to multi-decadal well-defined internal, intrinsic frequency and amplitude modulated variability. This is an important finding in our opinion.

Using Charleston as a surrogate, we propose that the terms weather, seasonal and sub-seasonal variability, and climate variability, both in the Charleston atmosphere and coastal ocean are all distinctly separate harmonics, with well-defined frequency and amplitude modulated banded peaks across a spectrum of multi-scaled phenomena. Weather resides at the high frequency end of the spectrum and climate is at the low frequency end of the spectrum. Seasonal and sub-seasonal variability are everything in between. The phenomena are distinct but interactively coupled and collectively they run the gamut from what we commonly refer to as weather to climate riding atop record length trends. In final summary, we have addressed and answered Bothe's question [11] of "when does weather become climate". Our answer is that weather and climate are distinct in the overall continuum of weather to climate. 


\section{Acknowledgements}

The authors acknowledge the National Science Foundation for support of the onset of this research under Grants CSR 1714015 and CSR 1763294 (PI's Gayes, Bao, Pietrafesa). The NOAA CWISE program at North Carolina State University (PI Pietrafesa) funded the collection and processing of the satellite data.

\section{Data Availability}

All data used in this study are archived at Coastal Carolina University and are available upon request, via electronic transfer, at zero cost, from the co-authors of this manuscript, ljpietra@ncsu.edu, sbao@coastal.edu, ptgayes@coastal.edu.

\section{Authors' Contributions}

LJP, PTG, SB conceived of the study and co-wrote the manuscript. TY developed the figures. DAD conceived of the wind-to-wave transform functions. DDC and TGC are students studying the Charleston environment.

\section{Conflicts of Interest}

The authors declare no conflict of interest and no personal circumstances or interest that could inappropriately influence the representation or interpretation of reported research results. The funders had no role in the design of the study, in the collection, analyses, or interpretation of data, in the writing of the manuscript or in the decision to publish the results.

\section{References}

[1] Pietrafesa, L.J., Janowitz, G.S. and Whitman, P.A. (1985) Physical Oceanographic Processes in the Carolina Capes. Atkinson, L.P., Menzel D.W. and Bush, K.A., Eds.,, Oceanography of the Southeastern U.S. Continental Shelf, Volume 2, American Geophysical Union, Washington DC, 23-32.

[2] Wu, Z. and Huang, N.E. (2009) Ensemble Empirical Mode Decomposition: A Noise-Assisted Data Analysis Method. Advances in Adaptive Data Analysis, 1, 1-41. https://doi.org/10.1142/S1793536909000047

[3] Huang, N.E., Shen, Z., Long, S.R., Wu, M.C., Shih, E.H., Zheng, Q., Tung, C.C. and Liu, H.H. (1998) The Empirical Mode Decomposition and the Hilbert Spectrum for Nonlinear and Non-Stationary Time Series Analysis. Proceedings of the Royal Society $A$, 454, 903-993. https://doi.org/10.1098/rspa.1998.0193

[4] Wu, Z., Huang, N.E., Long, S.R. and Peng, C.K. (2007) On the Trend, Detrending, and Variability of Nonlinear and Nonstationary Time Series. Proceedings of the National Academy of Sciences of the United States of America, 104, 14889-14894. https://doi.org/10.1073/pnas.0701020104

[5] Chao, S.Y. and Pietrafesa, L.J. (1980) The Sub-Tidal Response of Sea Level to Atmospheric Forcing in the Carolina Capes. Journal of Physical Oceanography, 10, 1246-1255. https://doi.org/10.1175/1520-0485(1980)010\%3C1246:TSROSL\%3E2.0.CO;2

[6] Bendat, J.S. and Piersol, A.G. (1986) Random Data, Analysis and Measurement Procedures. 2nd Edition, John Wiley and Sons, New York, 566 p. 
[7] Weisburg, R.H. and Pietrafesa, L.J. (1982) On the Correlation and Kinematics of the Surface Wind Field in the South Atlantic Bight. North Carolina State University Center for Marine \& Coastal Studies Report 82.01, 76 p.

[8] Weisburg, R.H. and Pietrafesa, L.J. (1983) Kinematics and Correlation of the Surface Windfield in the South Atlantic Bight. Journal of Geophysical Research, 88, 4593-4610. https://doi.org/10.1029/JC088iC08p04593

[9] Klinck, J.M., Pietrafesa, L.J. and Janowitz, G.S. (1981) Continental Shelf Circulation Induced by a Moving, Localized Wind Stress. Journal of Physical Oceanography, 11, 836-848. https://doi.org/10.1175/1520-0485(1981)011<0836:CSCIBA >2.0.CO;2

[10] Pietrafesa, L.J. and Gayes, P.T. (2019) Power Estimates of Coastal Zone Winds and Waves via Box, Whisker and Outlier Distributions at Atlantic Eastern Seaboard and Pacific Ocean Energy Sites. Oceanography \& Fisheries Open access Journal, 7, Article No. 55713. https://doi.org/10.19080/OFOAJ.2018.07.555713

[11] Bothe, O. (2019) When Does Weather Become Climate? Eos, 100, 2. https://doi.org/10.1029/2019EO131019 